\title{
Cultivo da levedura Phaffia rhodozyma (Xanthophyllomyces dendrorhous) em processo descontínuo alimentado para produção de astaxantina
}

\author{
Miriam Blümel Chociai*, lara Maria Pereira Machado, José Domingos Fontana, \\ Jorge Guido Chociai, Simone Bowles Busato, Tânia Maria Bordin Bonfim
}

Departamento de Farmácia, Universidade Federal do Paraná

*Correspondência:

M. B. Chociai

Departamento de Farmácia

Universidade Federal do Paraná

Rua Prof. Lothário Meissner, 3.400 -

Jd. Botânico

80210-170 - Curitiba - PR

E-mail: miriam@ufpr.br
A levedura Phaffia rhodozyma, produtora de astaxantina, pigmento carotenóide largamente empregado na aqüicultura de peixes e crustáceos, pode ser eficientemente cultivada num meio de cultura de baixo custo, à base de caldo de cana diluído 1:10 e uréia a $1 \mathrm{~g} / \mathrm{L}$. No entanto, a produção de biomassa e a formação do carotenóide sofrem a inibição pelo substrato (efeito "Crabtree"), limitando desta forma a utilização do caldo de cana com concentrações da fonte de carbono superiores a $20 \mathrm{~g} / \mathrm{L}$, importante consideração na produção industrial de astaxantina. No presente trabalho, o cultivo da levedura P. rhodozyma foi realizado em processo descontínuo alimentado, no qual se obteve produtividade volumétrica de 0,024 $\mathrm{mg}$ astaxantina/L.h. em relação aos 0,013 mg astaxantina/L.h. obtidos no cultivo controle, que não sofreu alimentação da fonte de carbono.
Unitermos:

- Astaxantina

- Phaffia rhodozyma

- Processo de fermentação descontínuo alimentado

\section{INTRODUÇÃO}

A astaxantina (3,3'-diidroxi- $\beta, \beta$-caroteno-4,4'diona) é um pigmento oxicarotenóide de cor vermelhoalaranjado presente no meio marinho, provavelmente originário de certas algas verdes e pequenos crustáceos. Estes organismos iniciam uma cadeia alimentar, que leva à pigmentação de outros animais, que, sendo incapazes de sintetizar os carotenóides, são coloridos devido a pigmentos oriundos de sua alimentação (Johnson, An, 1991). A astaxantina é empregada na avicultura (aumento na produção e coloração da carne de galinha e gema de ovos), mas sua principal aplicação é na aqüicultura de peixes (salmão, truta) e crustáceos (lagosta), para os quais a coloração da carne e/ou carapaça é um fator determinante na aceitação e no preço final do produto (Dike, Lettner, Zollitsch, 1992; Storebaken, No, 1992). Além disso, este carotenóide possui elevada atividade antioxidante, quando comparado com o $\beta$-caroteno e o $\alpha$-tocoferol (Terao, 1989). Por ser a síntese química da astaxantina complexa e de elevado custo, devido à presença dos centros quirais na sua estrutura molecular, existe um grande interesse no uso de fontes biológicas da mesma (Reynders, Rawlings, Harrison, 1996). Entre os organismos produtores de astaxantina, somente a alga verde Haematococcus pluvialis e a levedura Phaffia rhodozyma são atualmente consideradas de interesse industrial (Goodwin, 1992; Kobayashi, Kakizono, Nagai, 1993). Entre estes, merece atenção especial a leve- 
dura em função de sua qualidade nutricional e segurança na utilização como aditivo alimentar para peixes, suprindo além da astaxantina, vários conutrientes como proteínas, carboidratos e lipídios (Martin, Acheampong, Patel, 1993). A levedura Phaffia rhodozyma, além da glicose e xilose, fermenta outros açúcares (como a sacarose), que podem ser obtidos a partir do amido, materiais lignocelulósicos, beterraba e cana de açúcar (Vázquez, Santos, Parajó, 1997; Persike et al., 2002). Considerando a produção nacional estimada de 341 milhões de toneladas de cana de açúcar para a safra 2002/2003 e o baixo custo desta matéria prima (US\$ 13/tonelada) (Jornal da Cana, 2002), particularmente no Brasil, a utilização de derivados de cana como meios de cultivo tem sido uma estratégia promissora para o cultivo da levedura Phaffia rhodozyma.

Fontana et al. (1996a) relataram os primeiros resultados a respeito da produção de astaxantina empregando o caldo de cana como fonte de carbono em concentrações na ordem de $20 \mathrm{~g} / \mathrm{L}$. No entanto, quando esta concentração da fonte de carbono é aumentada, diminui-se drasticamente a produção da astaxantina (Bonfim, 1999). Isto é explicado pelo fato de que a levedura Phaffia rhodozyma apresenta o efeito "Crabtree", em que o crescimento celular e a produção de astaxantina ficam comprometidos pelo aumento residual de glicose (Reynders, Rawlings, Harrison, 1997). Neste caso específico, quando mudanças na concentração de nutrientes afetam a produtividade de um determinado metabólito microbiano, a utilização de um processo de fermentação descontínuo alimentado é uma técnica promissora, pois através dela a concentração de nutrientes alimentados à cultura líquida pode ser controlada voluntariamente pela taxa de alimentação (Yamane, Shimizu, 1980).

No presente trabalho, técnicas alternativas de fermentação foram testadas, buscando aumentar o rendimento do processo (biomassa e/ou pigmento carotenóide) pela manutenção de baixa concentração residual de açúcar, através do cultivo da levedura Phaffia rhodozyma em processo descontínuo alimentado.

\section{MATERIAL E MÉTODOS}

A levedura Phaffia rhodozyma, obtida originalmente do ATCC (referência 24202), foi mantida através de transferências periódicas a cada 2 meses, em meio de cultura sólido contendo $1 \mathrm{~g} / \mathrm{L}$ sacarose; $0,5 \mathrm{~g} / \mathrm{L}$ extrato de levedura e $0,5 \mathrm{~g} / \mathrm{L}$ peptona. Como fonte de carbono, foi utilizado o caldo de cana fresco, recentemente extraído, após prévia clarificação através de centrifugação a 6.000 rpm para a remoção de restos celulares e outros materiais contaminantes provenientes da moagem da cana. $\mathrm{O}$ meio de cultura básico foi preparado pela diluição do caldo de cana 1:10 em água destilada, suplementado com uréia na concentração de $1 \mathrm{~g} / \mathrm{L}$ como fonte de nitrogênio. Em seguida, o pH dos meios foi ajustado para 6,0 com solução de $\mathrm{NaOH} 2 \mathrm{M}$ e os mesmos foram esterilizados sob vapor fluente durante 30 minutos. Estes meios contém, aproximadamente, $20 \mathrm{~g} / \mathrm{L}$ de açúcares totais. O meio de cultura concentrado, a ser utilizado na alimentação diferencial dos cultivos, foi preparado de maneira semelhante, ajustandose a concentração de açúcares totais do caldo de cana para $100 \mathrm{~g} / \mathrm{L}$. Cada um dos cultivos foi inoculado com um volume de suspensão de cultura de 48 horas, de modo a obter uma densidade ótica (DO) entre 0,05 e 0,07 de absorbância a $650 \mathrm{~nm}$. Todos os cultivos (triplicata) foram realizados em frascos erlenmeyer de $250 \mathrm{~mL}$ contendo 50 $\mathrm{mL}$ do meio básico previamente esterilizado (relação de 1:5 entre o volume do meio e o volume do frasco a ser incubado), e incubados em agitador incubador a $24{ }^{\circ} \mathrm{C}$ a $125 \mathrm{rpm}$ com pulsos de alimentação variáveis. Em intervalos regulares houve a retirada de amostras $(0,24,48,72$ e 96 horas) para o acompanhamento do crescimento (através da determinação do peso seco) e do pH. Após centrifugação da amostra coletada foi realizada a dosagem de carboidratos totais no sobrenadante (Dubois et al., 1956). No sedimento (células) obtido após 96 horas de fermentação foi determinado o peso seco e o pigmento carotenóide. A astaxantina foi extraída a partir das células secas como se segue: a um tubo de ensaio contendo as células foram adicionados $2 \mathrm{~mL}$ de dimetilsulfóxido. Após 30 minutos foram acrescentados $6 \mathrm{~mL}$ de acetona, homogeneizados e centrifugados a $4.000 \mathrm{rpm}$ por $5 \mathrm{minu}-$ tos. No sedimento foi repetido o processo de extração. Aos sobrenadantes reunidos, foram adicionados $10 \mathrm{~mL}$ de solução aquosa de cloreto de sódio $200 \mathrm{~g} / \mathrm{L}$ e $10 \mathrm{~mL}$ de éter de petróleo. A fase etérea foi separada, seca por filtração através de sulfato de sódio anidro, transferida para um balão volumétrico de $25 \mathrm{~mL}$ e o volume foi completado com éter de petróleo. A absorbância da solução foi lida em espectrofotômetro a $474 \mathrm{~nm}$. O cálculo da concentração de astaxantina foi feito a partir de dados da literatura, da absortividade específica para as xantofilas a $474 \mathrm{~nm}$ : A = 1.600 (Bonfim, 1999; Goodwin, 1992).

Em todas as coletas realizadas, verificou-se a pureza dos cultivos, utilizando o teste de Gram (coloração de Gram) e pela análise da lâmina contendo material a fresco em microscópio (Bier, 1980). Paralelamente, um cultivo denominado controle (sem alimentação) foi utilizado para comparação dos resultados, principalmente de biomassa e astaxantinogênese. 


\section{RESULTADOS E DISCUSSÃO}

Trabalhos de Fontana et al. (1996a, 1996b, 1997), demonstraram a eficiente produção da astaxantina em processo de fermentação descontínuo, utilizando o caldo de cana como fonte de carbono em concentrações na ordem de $20 \mathrm{~g} / \mathrm{L}$, suplementado com pequenas concentrações de uréia como fonte de nitrogênio $(1 \mathrm{~g} / \mathrm{L})$.

Quando a levedura Phaffia rhodozyma foi cultivada em processo descontínuo, em caldo de cana diluído 1:10 (20 g/L açúcares totais) suplementado com uréia a $1 \mathrm{~g} / \mathrm{L}$ obtiveram-se os valores da Figura 1 (cultivo controle). Durante o início da fase de crescimento exponencial (velocidade específica de crescimento $=0,14 \mathrm{~h}^{-1}$ ) o $\mathrm{pH}$ diminuiu, voltando a aumentar já a partir das 24 horas de cultivo, fato anteriormente observado por Johnson e An (1991) segundo os quais a Phaffia rhodozyma excreta um intermediário carbônico durante a fase inicial de crescimento, por exemplo um álcool, ácido acético ou um intermediário do ciclo do ácido cítrico, que posteriormente é reassimilado e estimula a carotenogênese. $\mathrm{O}$ consumo de açúcares totais é bastante intenso nas primeiras horas, verificando-se que $92 \%$ daqueles inicialmente disponíveis foram consumidos nas primeiras 48 horas de cultivo.

Para contornar o efeito "Crabtree", experimentos foram realizados em processo descontínuo alimentado utilizando-se como meio de alimentação, o caldo de cana concentrado com uma concentração de açúcares totais de $100 \mathrm{~g} / \mathrm{L}$. Este meio foi utilizado sem suplementação da fonte de nitrogênio, uma vez que Acheampong e Martin (1995) verificaram que a carotenogênese é estimulada pela limitação de nitrogênio, quando fungos são cultivados em culturas superficiais, sem a presença da uréia. Reynders, Rawlings e Harrison (1996) empregaram o melaço para o cultivo da Phaffia rhodozyma, usando um método de alimentação em série da fonte de carbono.

A Figura 2 mostra o perfil da cultura alimentada com $2 \mathrm{~mL}$ de caldo concentrado após 48 e 72 horas de cultivo, considerando o perfil do consumo de açúcares verificado no cultivo controle e a observação de Johnson e Lewis (1979) os quais descreveram que a produção de astaxantina em Phaffia rhodozyma ocorre principalmente durante a fase de crescimento exponencial. No acompanhamento do crescimento celular no tempo de 96 horas, obtiveram-se valores de produtividade horária total da biomassa formada $\left(\mathrm{r}_{\text {total }}\right)$ de $0,075 \mathrm{~g} / \mathrm{L} . \mathrm{h}$, comparativamente aos $0,038 \mathrm{~g} / \mathrm{L}$.h observados no cultivo que não sofreu alimentação da fonte de carbono (controle).

Alimentando-se a cultura com o mesmo volume de caldo concentrado após 48, 72 e 96 horas, obtiveram-se as curvas da Figura 3, muito semelhantes àquelas obtidas quando a cultura foi alimentada apenas durante a fase exponencial de crescimento (48 e 72 horas).

A determinação da biomassa microbiana através do peso seco (DCW) e a quantificação da astaxantina foi realizada em todos os cultivos do presente trabalho, ao final de 96 horas de incubação, tempo no qual é máxima a concentração de astaxantina (Bonfim, 1999).

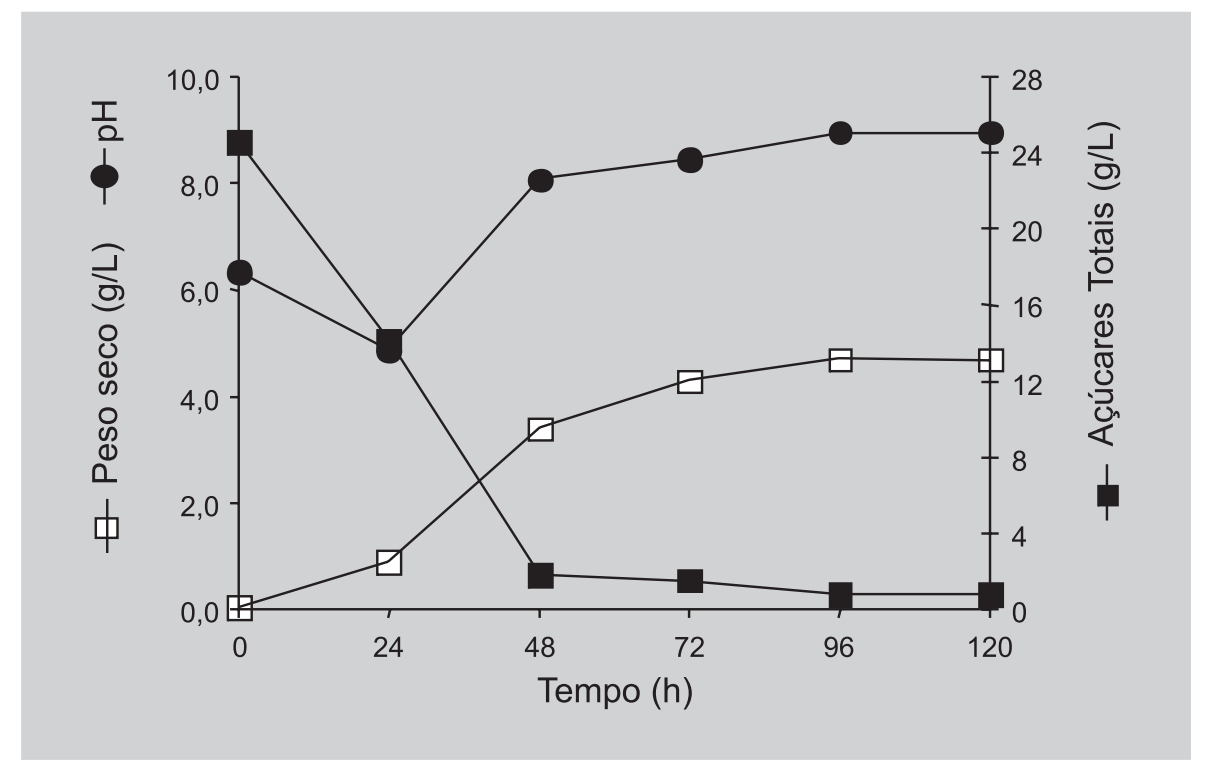

FIGURA 1 - Cultivo da levedura Phaffia rhodozyma em caldo de cana diluído (concentração de açúcares totais de $20 \mathrm{~g} / \mathrm{L})$ e $1 \mathrm{~g} / \mathrm{L}$ de uréia. 


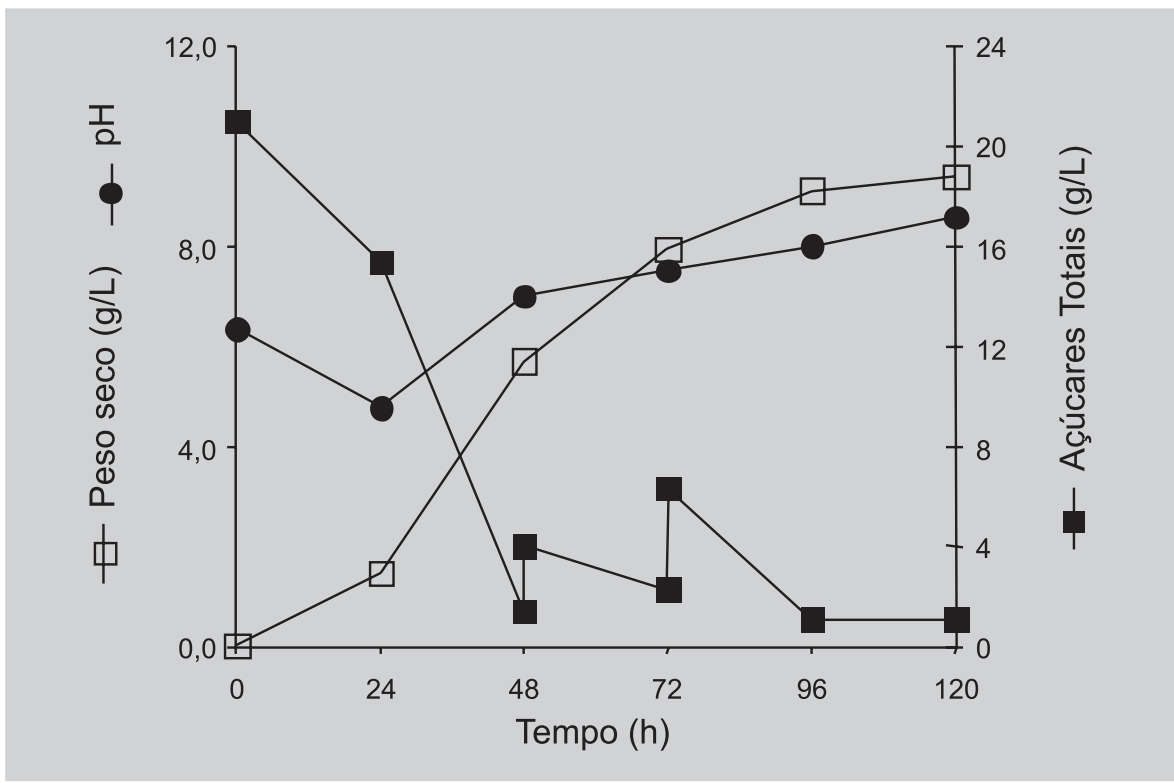

FIGURA 2 - Cultivo da levedura Phaffia rhodozyma em caldo de cana diluído 1:10 e $1 \mathrm{~g} / \mathrm{L}$ de uréia, alimentado após 48 e 72 horas com $2 \mathrm{~mL}$ de caldo concentrado (concentração de açúcares totais de $100 \mathrm{~g} / \mathrm{L}$ ).

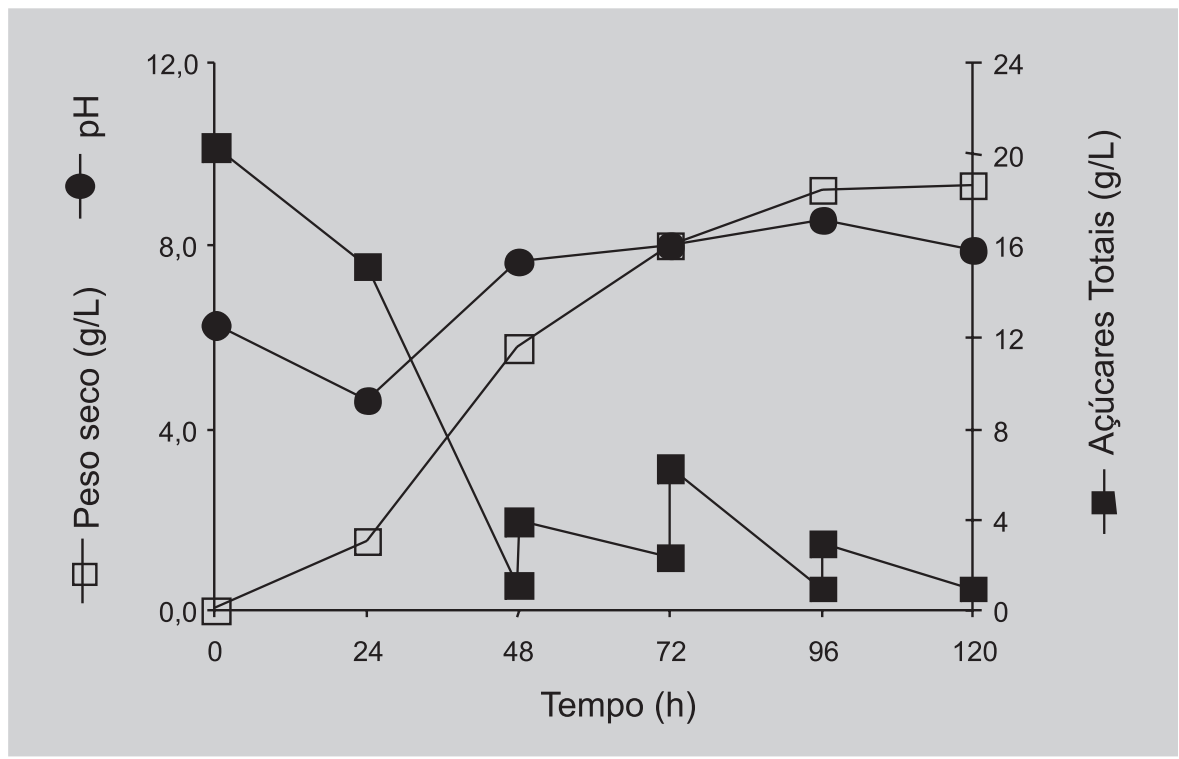

FIGURA 3 - Cultivo da levedura Phaffia rhodozyma em caldo de cana diluído 1:10 e $1 \mathrm{~g} / \mathrm{L}$ de uréia, alimentado após 48, 72 e 96 horas e com $2 \mathrm{~mL}$ de caldo concentrado (concentração de açúcares totais de $100 \mathrm{~g} / \mathrm{L}$ ).

A comparação da biomassa produzida com a formação do pigmento carotenóide no cultivo controle em relação àquele alimentado, pode ser feita pela análise da Figura 4. No cultivo alimentado após 48 e 72 horas, houve a formação de $9,12 \mathrm{~g} / \mathrm{L}$ de peso seco, valor significativamente maior que aquele observado no cultivo que não sofreu alimentação da fonte de carbono $(4,7 \mathrm{~g} / \mathrm{L})$.
Com relação ao pigmento carotenóide, neste mesmo cultivo alimentado (após 48 e 72 horas), obtiveram-se 2,37 $\mathrm{mg}$ astaxantina/L contra $1,34 \mathrm{mg} / \mathrm{L}$ no cultivo controle. Relacionando-se a produtividade volumétrica do processo, foram obtidos valores de $0,024 \mathrm{mg}$ astaxantina/L.h no cultivo alimentado e apenas de $0,013 \mathrm{mg}$ astaxantina/L.h no cultivo controle, com teores de 0,089 e $0,056 \mathrm{mg}$ de 


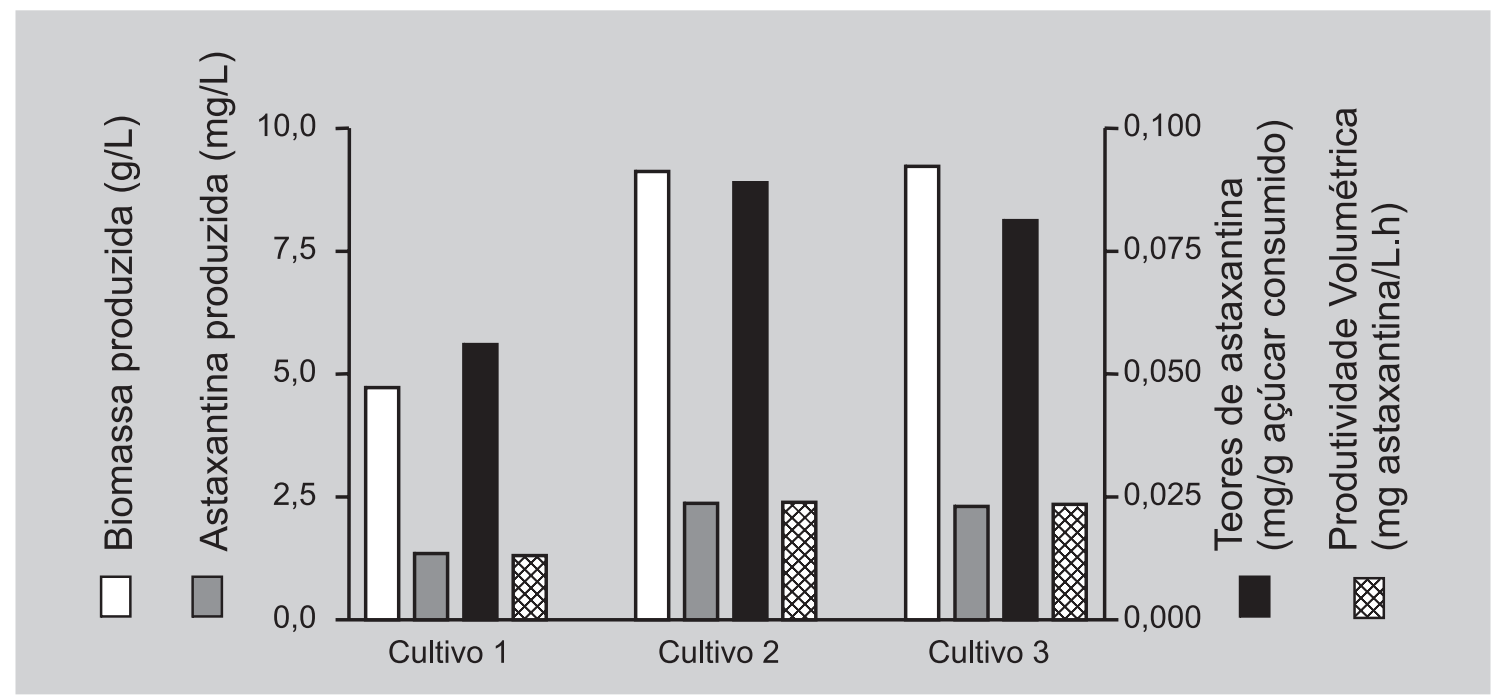

FIGURA 4 - Produção de astaxantina e de biomassa de Phaffia rhodozyma em sistema de cultivo descontínuo (cultivo 1), descontínuo alimentado após 48 e 72 horas (cultivo 2) e descontínuo alimentado após 48, 72 e 96 horas (cultivo 3).

astaxantina/g açúcar consumido, respectivamente, comprovando que pela manutenção de baixa concentração residual de açúcar, se consegue suplantar o efeito da inibição pelo substrato sobre o crescimento celular (Yamane et al., 1997) e sobre a astaxantinogênese, já que esta é comprovadamente associada ao crescimento da levedura Phaffia rhodozyma (Fontana et al., 1997).

\section{CONCLUSÃO}

Estes resultados permitem concluir que, aliando a utilização do caldo de cana, matéria-prima barata e abundante em nosso país, com a introdução de um processo de fermentação descontínuo alimentado para o cultivo da levedura Phaffia rhodozyma, consegue-se aumentar a produtividade do processo em $84 \%$, comparativamente ao cultivo controle.

\section{ABSTRACT \\ Cultivation of Phaffia rhodozyma (Xanthophyllomyces dendrorhous) yeast in discontinuous system to obtain astaxanthin}

The yeast Phaffia rhodozyma produces astaxanthin, a carotenoid pigment widely applied in fish and crustaceous cultivation. This yeast can be efficiently cultured in a low cost medium, sugar cane broth diluted 1:10 and supplemented with $1 \mathrm{~g} / \mathrm{L}$ urea. However, the biomass and astaxanthin production undergo inhibition by the substrate (Crabtree effect), limiting the utilization of su- gar cane broth up to $20 \mathrm{~g} / \mathrm{L}$ total sugar concentration. Therefore, this effect must be considered during the industrial production of astaxanthin. In the present work, using fed batch system to cultivate P. rhodozyma we were able to obtain $0.024 \mathrm{mg}$ astaxanthin/l.h compared to $0.013 \mathrm{mg}$ astaxanthin/l.h obtained by the discontinuous cultivation system.

UNITERMS: Astaxanthin. Phaffia rhodozyma. Fed batch cultivation.

\section{REFERÊNCIAS BIBLIOGRÁFICAS}

ACHEAMPONG, E. A., MARTIN, A. M. Kinetic studies on the yeast Phaffia rhodozyma. J. Basic Microbiol., Berlin, v. 35, n. 3, p. 147-155, 1995.

BIER, O. Bacteriologia e imunologia. São Paulo: Melhoramentos, $1980.838 \mathrm{p}$.

BONFIM, T. M. B. Produção de astaxantina pela levedura Phaffia rhodozyma (Xanthophyllomyces dendrorhous) a partir de meios de cultura de baixo custo. Curitiba, 1999. 158 p. [Tese de Doutorado em Ciências, Setor de Ciências Biológicas, Universidade Federal do Paraná].

DIKE, A. O., LETTNER, F., ZOLLITSCH, W. The supplementation of layers feed with the yeast - Phaffia rhodozyma - as pigment carrier. Archiv für geflügelkunde, Kingston, v. 5, p. 205-209, 1992. 
DUBOIS, M., GILLES, K. A., HAMITON, J. K., REBERS, P. A., SMITH, F. Colorimetric method for determination of sugars and related substances. Anal. Chem., Washington, v. 28, n. 3, p. 350-356, 1956.

FONTANA, J. D., GUIMARÃES, M. F., MARTINS, N. T., FONTANA, C. A., BARON M. Culture of the astaxanthinogenic yeast Phaffia rhodozyma in low-cost media. Appl. Biochem. Biotechonol., Totowa, v. 57/58, p. 413-422, 1996a.

FONTANA, J. D., CZECZUGA, B., BONFIM, T. M. B., CHOCIAI, M. B., OLIVEIRA, B. H., GUIMARÃES, M. F., BARON, M. Bioproduction of carotenoids: the comparative use of raw sugarcane juice and depolymerized bagasse by Phaffia rhodozyma. Biores. Technol., v. 58, p. 121-125, 1996 b.

FONTANA, J. D., CHOCIAI, M. B., BARON, M., GUIMARÃES, M. F., MARASCHIN, M., ULHOA, C., FLORÊNCIO, J. A., BONFIM, T. M. B. Astaxanthinogenesis in the yeast Phaffia rhodozyma: optimization of low-cost culture media and yeast cellwall lysis. Appl. Biochem. Biotechnol., Washington, v. 63-65, p. 305-314, 1997.

GOODWIN, T. W. Distribution of carotenoids. Methods in enzimology, New York, v. 213, p. 167-172, 1992.

JOHNSON, E. A., AN, G.H. Astaxanthin from microbial sources. Crit. Rev. in Biotechnol., Boca Raton, v. 11, n. 4, p. 297-326, 1991.

JOHNSON, E. A., LEWIS, M. J. Astaxanthin formation by the yeast Phaffia rhodozyma. J. Gen. Microbiol., Reading, v. 115, p. 173-183, 1979.

JORNAL DA CANA. Disponível em: <http:// www.jornalcana.com.br/> Acesso em: 27 maio. 2002.

KOBAYASHI, M., KAKIZONO, T., NAGAI, S. Enhanced carotenoid biosynthesis by oxidative stress in acetateinduced cyst cells of a green unicellular alga Haematococcus pluvialis. Appl. Environm. Microbiol., v. 59, p. 867-873, 1993.

MARTIN, A. M.; ACHEAMPONG, E.; PATEL, T. R. Production of astaxanthin by Phaffia rhodozyma using peat hydrolysates as substrate. J. Chem. Technol. Biotechnol., v. 58, p. 223-230, 1993.
PERSIKE, D. S., BONFIM, T. M. B., SANTOS, M. H. R., LYNG, S. M. O., CHIARELLO, M. D., FONTANA, J. D. Invertase and urease activities in the carotenogenic yeast Xanthophyllomyces dendrorhous (formerly Phaffia rhodozyma). Biores. Technol., v. 82, p. 79-85, 2002.

REYNDERS, M. B., RAWLINGS, D. E., HARRISON, S. T. L. Demonstration of the Crabtree effect in Phaffia rhodozyma during continuous and fed-batch cultivation. Biotechnol. Lett., Middlesex, v. 19, n. 6, p. 549-552, 1997.

REYNDERS, M. B., RAWLINGS, D. E., HARRISON, S. T. L. Demonstration of the crabtree effect in Phaffia rhodozyma during continuous and fed-batch cultivation. Biotechnol. Lett., Middlesex, v. 19, n. 6, p. 549-552, 1997.

REYNDERS, M. B., RAWLINGS, D. E., HARRISON, S. T. L. Studies on the growth, modelling and pigment production by the yeast Phaffia rhodozyma during fedbatch cultivation. Biotechnol. Lett., Middlesex, v. 18, n. 6, p. 649-654, 1996.

STOREBAKKEN, T., NO, H. K. Pigmentation of rainbow trout. Aquaculture, Amsterdam, v.100, p. 209-229, 1992.

TERAO, J. Antioxidant activity of b-carotene-related carotenoids in solution. Lipids, v. 24, p. 659-661, 1989.

VÁZQUEZ, M., SANTOS, V., PARAJÓ, J. C. Effect of the carbon source on the carotenoid profiles of Phaffia rhodozyma strains. J. Ind. Microbiol. Biotechnol., v. 19, p. 263-268, 1997.

YAMANE, T., SHIMIZU, S. Fed batch techniques in microbial processes. Adv. Biochem. Eng. Biotechnol., v. 30, p. 147-194, 1980.

YAMANE, Y. I., HIGASHIDA, K., NAKASHIMADA, Y., KARIZONO, T., NISHIO, N. Astaxanthin production by Phaffia rhodozyma enhanced in fed-batch culture with glucose and ethanol feeding. Biotechnol. Lett., Middlesex, v. 19, n. 11, p. 1109-1111, 1997.

Recebido para publicação em 01 de julho de 2002. 